\author{
Yunhuan Sui \\ Xingzhong Zhang \\ Long Guo \\ Dianfeng $X u$
}

https://doi.org/10.21278/TOF.43407

ISSN 1333-1124

eISSN 1849-1391

\title{
MICROSTRUCTURAL STUDY OF HIGH TEMPERATURE CREEP IN Q460E STEEL BASED ON THE SOLIDIFICATION METHOD
}

\begin{abstract}
Summary
A tensile creep test has been carried out to study the high temperature creep mechanism of Q460E steel and thus develop a better understanding about how the creep phenomenon affects the performance of a cast slab. Because the heating process in the solidification method is more similar to the actual solidification process of casting a slab, the high temperature tensile creep test was conducted by using the solidification method. Further observation of the microstructure was carried out after the tensile creep test has been carried out. The microstructure of the Q460E steel after the high temperature tensile creep test and water quenching observed with a metallographic microscope revealed mainly martensite and retained austenite. From the observation with a transmission electron microscope (TEM) it could be found that dislocation and its substructure were the root cause which triggered high temperature creep deformation of the Q460E steel. In addition, the formation of a subboundary also provided the impetus to creep deformation.
\end{abstract}

Key words: $\quad$ Q460E steel; high temperature creep behaviour; solidification method; microstructure observation; continuous casting

\section{Introduction}

The Q460 steel grade is extensively used in many applications, such as bridges, vehicles, boilers, high pressure vessels, oil and gas pipelines, large-scale steel structures etc. An obvious creep phenomenon will occur in Q460 steels when they are used in conditions of high temperature. Creep means that when a body is subjected to a constant external force, its deformation, stress and external force do not have a one-to-one relationship, and this kind of deformation is irreversible even if the stress is less than the yield strength. Creep is usually defined in a narrow sense. It mainly means that under the condition of constant temperature and stress, the object will deform slowly with the passing of time [1]. The mechanical and creep properties of the Q460 steel were tested at high temperatures. The expressions of creep deformation depending on temperature and stress were formulated from the test data based on different classical creep models [2, 3].

When a metal is subjected to a temperature of $0.3 \sim 0.4$ times or more its melting point, the creep phenomenon will be very obvious and the creep rate will accelerate significantly $[4$, 
5]. During the continuous casting process of steel, the deformation of bending and straightening is often accompanied by the solidification from liquid to solid, and the minimum surface temperature of a slab is higher than $900{ }^{\circ} \mathrm{C}$, which is more than 0.4 times its melting point. Therefore, the creep phenomenon has an important impact on the deformation process of a continuous cast slab [6]. Different material constitutive models of steel subjected to high temperatures were analyzed and compared. The significant impact that the strain rate had on the deformation of a continuous cast slab at different high temperatures was studied [7].

All these studies show that creep has an important effect on the calculation and analysis of the continuous casting process and should not be ignored. An overwhelming majority of creep deformation cases may be regarded as one of the negative effects causing failure, but there is still a part of creep deformation benefitting the production [8]. Only a few studies have focused on how to take advantage of the positive aspect of creep deformation. Q345C steel was chosen to test the plasticity and creep property under the high temperature condition. The thermophysical parameters and minimum creep strain rate equation were obtained by fitting the test data. And a new casting curve of a current continuous casting machine was designed on the basis of the high temperature creep properties of the Q345C steel. Therefore, the cast slab could be straightened by fully utilizing the high temperature creep deformation, and the cracks that developed during the straightening process could be effectively avoided. In such a way, the quality of a continuous cast slab would be improved [9]. Tests for thermoplasticity and high temperature creep performance of the Q460E steel were carried out. After that, the thermophysical parameters and creep constitutive equation were obtained from the test data. Then, they were applied in the process of straightening a continuous cast slab so as to utilize the creep deformation to complete the straightening [10]. It can be seen that the high temperature creep property has a positive impact on the production and application of materials.

In order to make use of the good aspects of creep and avoid its negative aspects, it is necessary to study the creep mechanism in depth. Consequently, the high temperature creep property of the Q460E steel was tested in this study at $1,000{ }^{\circ} \mathrm{C}$ and $1,050{ }^{\circ} \mathrm{C}$. Then, the specimens were observed after the test under an optical microscope and a TEM to study the microstructure of the steel when the creep deformation occurred. The ultimate purpose of the study is to facilitate the process of actual production and improve the productivity.

\section{Materials and methods}

\subsection{High temperature tensile creep test}

High temperature tensile test is often carried out by using a heating method and a solidification method. Some researchers have found that it is closer to the real steel solidification and the subsequent cooling process if the solidification method was adopted to study the high temperature mechanical property $[11,12]$. Based on this, a high temperature tensile creep test of the Q460E steel using the solidification heating mechanism was conducted on a Gleeble-3800 thermal and mechanical simulation testing machine, manufactured by DSI, USA. In this paper, the solidification method refers to heating specimens to the liquidus temperature $\left(T_{L}\right)$ gradually in the vacuum condition; then cooling them to the test temperature $\left(T_{E}\right)$ and stretching them under constant stress. The testing process is shown in Fig. 1. 


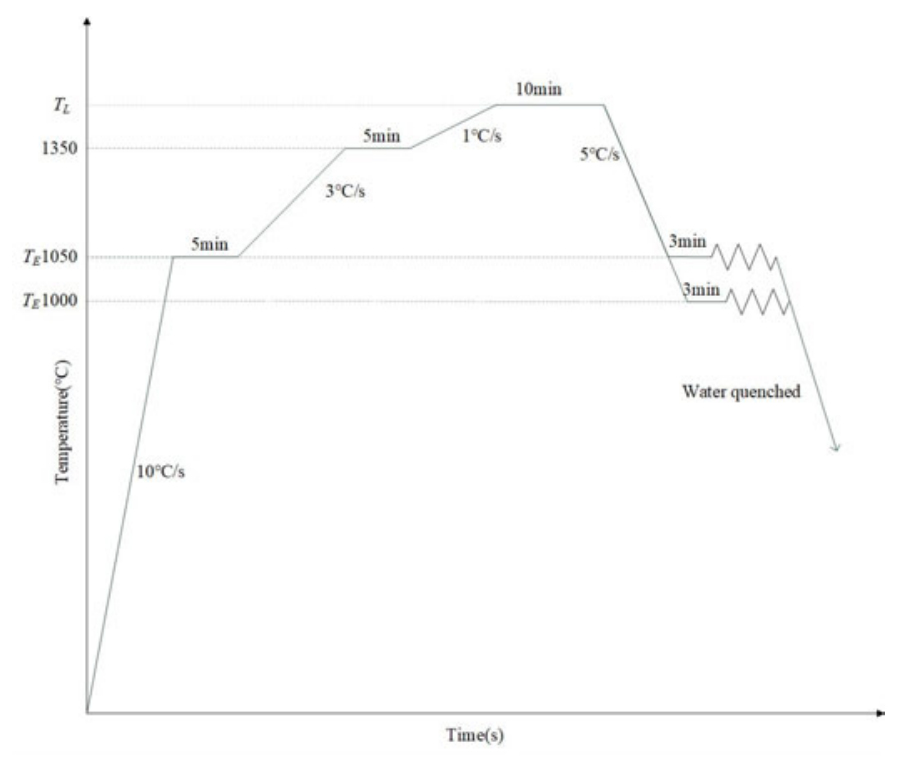

Fig. 1 Process of tensile creep test.

The specimens to undergo the high temperature tensile creep test were taken from a continuous slab of the Q460E steel which was produced by a steelworks. The chemical composition of Q460E is given in Table 1.

Table 1 Chemical composition of Q460E. (Mass.\%)

\begin{tabular}{|c|c|c|c|c|c|c|c|c|}
\hline Steel/Elem. & $\mathrm{C}$ & $\mathrm{Si}$ & $\mathrm{Mn}$ & $\mathrm{P}$ & $\mathrm{S}$ & $\mathrm{Cr}$ & $\mathrm{Ni}$ & $\mathrm{Fe}$ \\
\hline $\mathrm{Q} 460 \mathrm{E}$ & 0.20 & 0.50 & 1.00 & 0.03 & 0.03 & 0.70 & 0.70 & Balance \\
\hline
\end{tabular}

According to the dimensional requirement of the Gleeble-3800 thermal and mechanical simulation testing machine for tensile specimens, a $10 \mathrm{~mm}$ diameter and $120 \mathrm{~mm}$ long bar with screw threads on both ends, as shown in Fig. 2, was used for the tensile test. It is noteworthy that before the test a quartz tube of $\Phi 10.4 \mathrm{~mm} \times 30 \mathrm{~mm}$ in size needs to be set in the middle of the specimen to support and protect the melting zone, i.e. to prevent the molten steel from spilling [13].

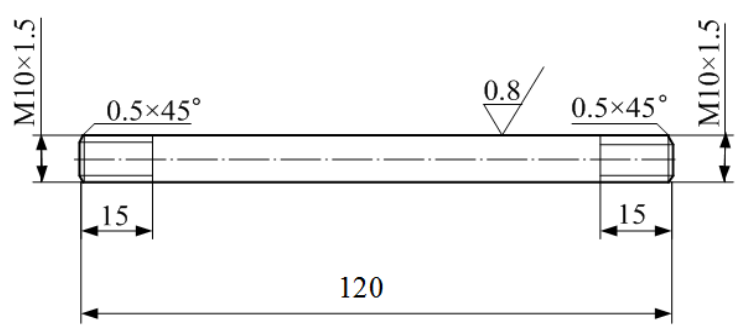

Fig. 2 Tensile specimen dimensions.

Referring to the previous study [14], the tensile stress value was set below the yield stress so that merely the creep strain could be obtained rather than the plastic strain. The parameters of the tensile creep test are listed in Table 2. Water quenching of the tensile specimens to preserve their microstructure and morphology was rapidly performed just after the creep deformation.

Table 2 Parameters of constant tensile creep test

\begin{tabular}{|c|c|}
\hline Temperature $/{ }^{\circ} \mathrm{C}$ & Applied stress/MPa \\
\hline 1,000 & 10,20 \\
\hline 1,050 & 10,20 \\
\hline
\end{tabular}




\subsection{Microstructural investigation}

First, small cylinder samples were cut from the specimens upon completion of the high temperature tensile creep test and water quenching. After being coarsely ground to obtain a flat surface, the samples were fine ground by using a fine abrasive paper. And then, the ground samples were polished on an infinitely variable speed metallographic polishing machine with fine velvet. After the polishing, the samples were cleaned with clear water and corroded with a $4 \%$ nitric acid alcohol solution [15]. Subsequently, the microstructure was observed and the images were collected from a metallographic microscope.

In addition, to study the internal structure of the crystal such as dislocation during the high temperature creep process, a TEM was utilized. After the tensile creep test the thickness of the specimens was mechanically reduced to $0.5 \mathrm{~mm}$. Afterwards, by applying water grinding, the samples were polished from coarse to fine until they were thinned to $40 \sim 50 \mu \mathrm{m}$. Then, the pre-polished samples were twin-jet electropolished on a double jet polishing machine with a $4 \%$ nitric acid alcohol solution as an electrolyte solution. The temperature was set to $30{ }^{\circ} \mathrm{C}$, and the voltage was set to $30 \mathrm{~V}$.

\section{Results and discussion}

\subsection{High temperature tensile creep test}

A typical creep curve shows a relationship between strain and time drawn on the basis of a constant temperature and load test data. It is generally divided into three stages, namely the transitional creep stage (the first stage), the steady-state creep stage (the second stage) and the accelerated creep stage (the tertiary stage) [1]. Fig. 3 shows the relationship between the creep strain and the time of the Q460E steel at $1,000{ }^{\circ} \mathrm{C}$ and $1,050{ }^{\circ} \mathrm{C}$ when the tensile stress is $10 \mathrm{MPa}$ and $20 \mathrm{MPa}$, respectively. The instantaneous strain of the initially applied force was ignored in the graphs, and the data were extracted from the time when the stress value was stable.

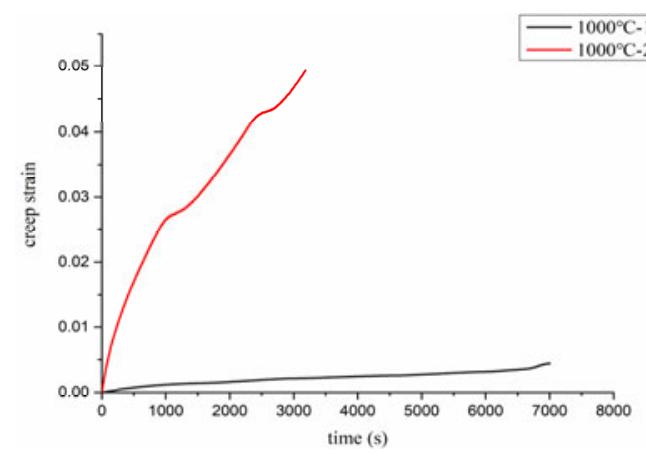

(a)

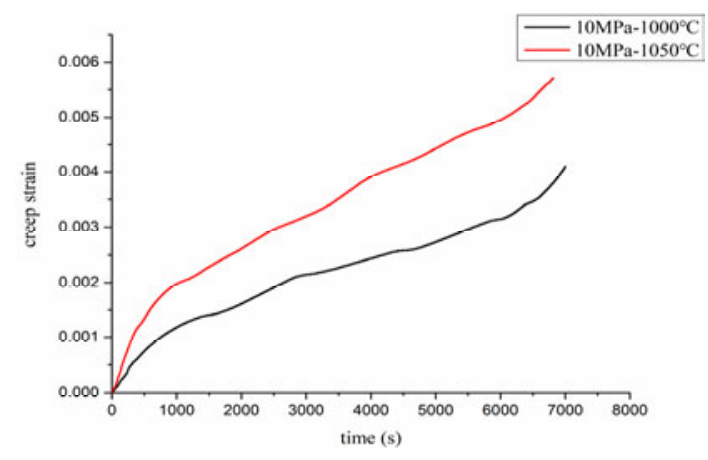

(c)

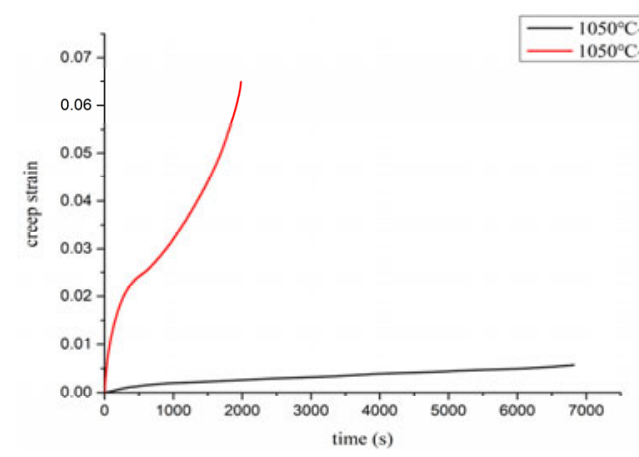

(b)

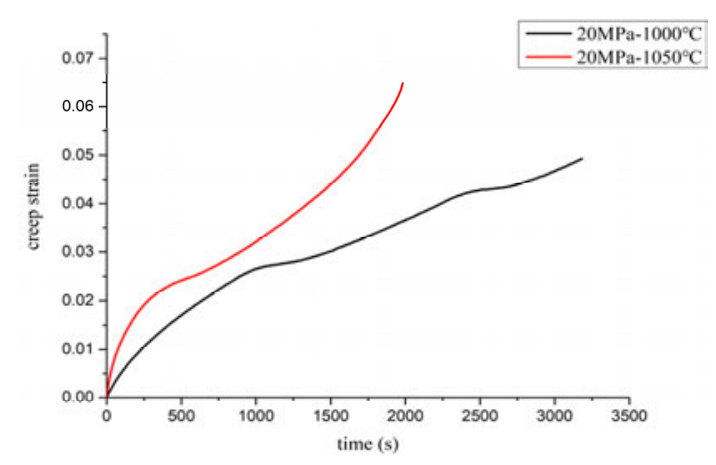

(d)

Fig. 3 Curves showing the relationship between creep strain and time of Q460E: (a) creep curves at 1,000 ${ }^{\circ} \mathrm{C}$; (b) creep curves at $1,050{ }^{\circ} \mathrm{C}$; (c) creep curves at $10 \mathrm{MPa}$; (d) creep curves at $20 \mathrm{MPa}$. 
As it can be seen from Fig. 3(a), when the tensile stress was set to $10 \mathrm{MPa}$ at the temperature of $1,000{ }^{\circ} \mathrm{C}$, the first stage of the creep curve was relatively obvious. It took about 1,500 s to enter the second stage which lasted until the end of the test. When the tensile stress was $20 \mathrm{MPa}$, the first stage of creep was relatively shorter and lasted for about 1,000 s, then it began to enter the steady-state creep stage that also lasted for the rest of the test process. Similarly, in Fig. 3(b), when the temperature was $1,050{ }^{\circ} \mathrm{C}$, the trend of the curve showing that the creep strain varied with time was largely in accordance with that presented in Fig. 3(a). Under the tensile stress of $10 \mathrm{MPa}$, the first stage of creep lasted about $750 \mathrm{~s}$, and the second stage of the creep deformation started and continued until the end of the test. When the tensile stress was set to $20 \mathrm{MPa}$, the first stage of creep only sustained for $480 \mathrm{~s}$, then entered the steady-state creep stage and remained in that stage until the end of the test. Fig. 3(c) shows that the creep strain at $1,050{ }^{\circ} \mathrm{C}$ was larger than that at $1,000{ }^{\circ} \mathrm{C}$ when the tensile stress was $10 \mathrm{MPa}$, which indicated that during roughly the same deformation period, the higher the test temperature was, the higher the creep deformation rate was and the more intense the creep process was. A similar situation could be observed in Fig. 3(d).

\subsection{Observation of the microstructure}

Fig. 4 shows the metallographic structure upon completion of the high temperature tensile creep test carried out under different conditions.

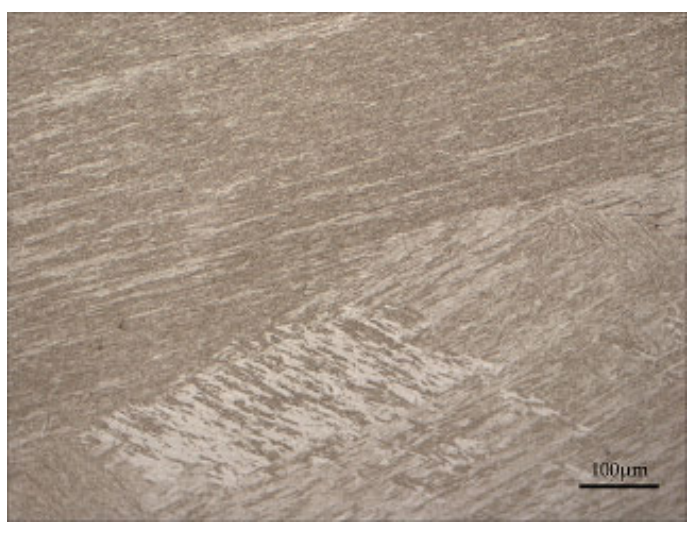

(a)

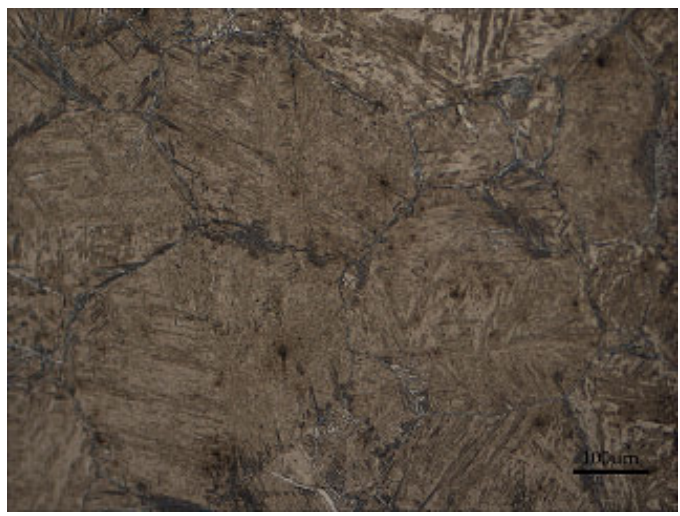

(c)

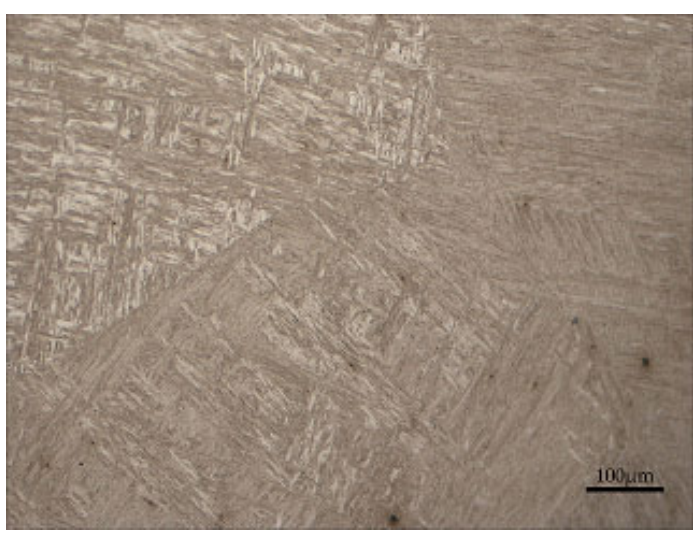

(b)

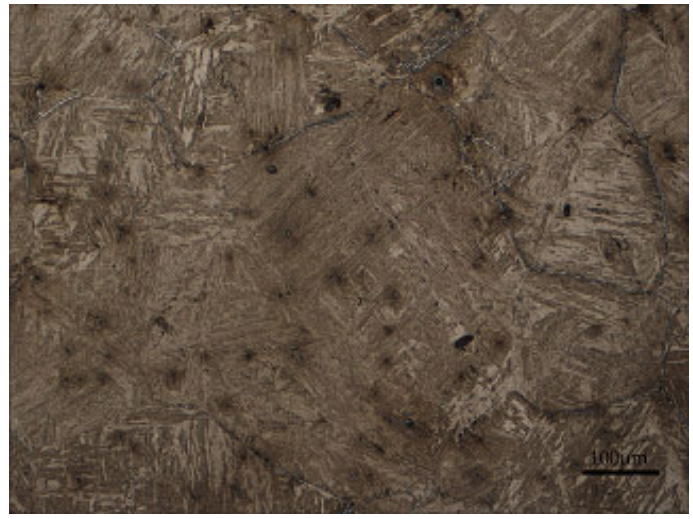

(d)

Fig. 4 Metallographic structure after tensile creep test performed under different test conditions: (a) $1,000{ }^{\circ} \mathrm{C}, 10 \mathrm{MPa}$; (b) $1,000{ }^{\circ} \mathrm{C}, 20 \mathrm{MPa}$; (c) $1,050{ }^{\circ} \mathrm{C}, 10 \mathrm{MPa}$; (d) $1,050{ }^{\circ} \mathrm{C}, 20 \mathrm{MPa}$.

In general, as Figs. 4(a)-4(d) show, the structure of the Q460E steel specimens after the high temperature tensile creep test and water quenching had been completed was mainly lath martensite and retained austenite. Laths of martensite were separated by small angle grain boundaries, while larger angles existed between bunches of martensite. 
It could be observed from Fig. 4(a) and Fig. 4(b) that when the test temperature was set to $1,000{ }^{\circ} \mathrm{C}$ the crystalline grains of the specimen subjected to the stress of $20 \mathrm{MPa}$ were smaller than those subjected to the stress of $10 \mathrm{MPa}$. Similarly, in Fig. 4(c) and Fig. 4(d), when the temperature was $1,050{ }^{\circ} \mathrm{C}$, the crystalline grains of the specimen became smaller as the stress increased. Some carbide particles were separated from martensite and were distributed in grains and boundaries, which made the grain boundaries appear more clearly. In addition, Fig. 4(c) and Fig. 4(d) show some bainite at the grain boundary. Also, the amount of bainite decreased when the tensile stress value increased. By contrasting Fig. 4(a) with Fig. 4(c), it could be found that when the value of the tensile stress was set to $10 \mathrm{MPa}$ and the temperature increased, the crystalline grains were refined clearly and the grain boundaries were easier to distinguish. Likewise, in Fig. 4(b) and Fig. 4(d), under the same stress value of $20 \mathrm{MPa}$, the grain refinement became more distinct; also, more carbide precipitated from martensite, which made the grain boundaries become more obvious. Additionally, a more specific microstructure of the above mentioned specimens was obtained by the TEM, as shown in Figs. 5-7.

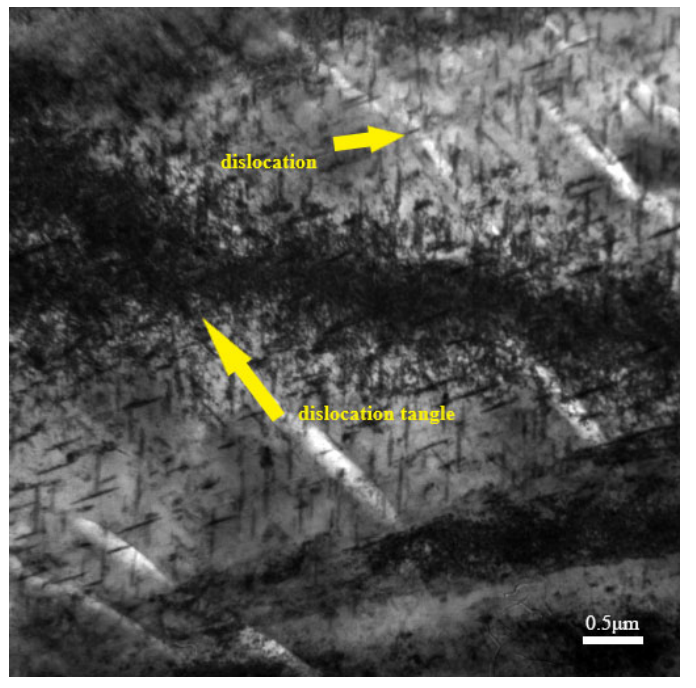

(a)

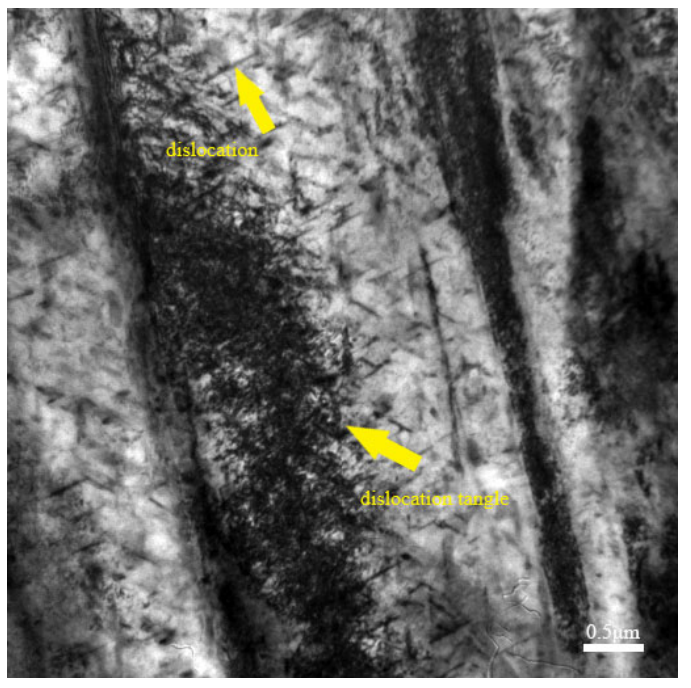

(c)

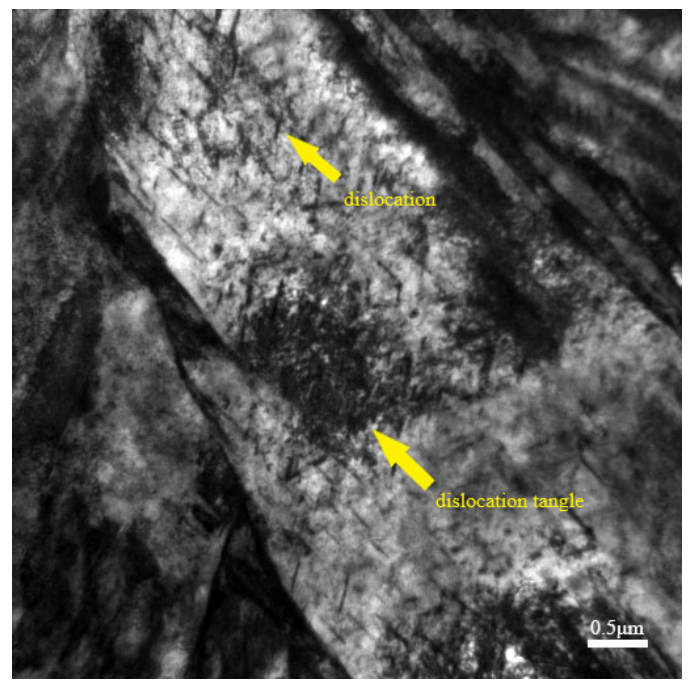

(b)

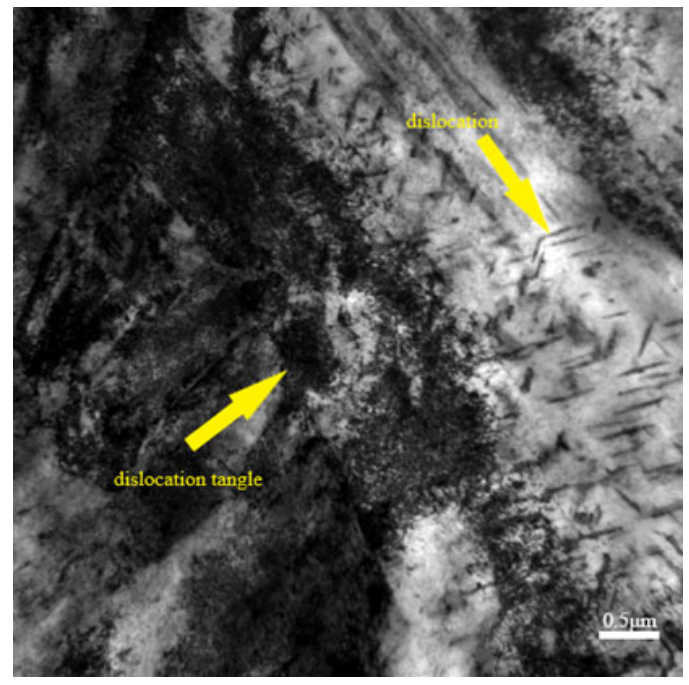

(d)

Fig. 5 TEM metallography under different conditions when magnification was 20,000 times: (a) $1,000{ }^{\circ} \mathrm{C}, 10 \mathrm{MPa}$; (b) $1,000{ }^{\circ} \mathrm{C}, 20 \mathrm{MPa}$; (c) $1,050{ }^{\circ} \mathrm{C}, 10 \mathrm{MPa}$; (d) $1,050{ }^{\circ} \mathrm{C}, 20 \mathrm{MPa}$. 
It could be observed from Fig. 5 that at different test temperatures and stresses there were numerous obvious dislocations. Moreover, as Fig. 5(a) shows, under the test condition of $1,000{ }^{\circ} \mathrm{C}$ and $10 \mathrm{MPa}$, a large number of dislocations were distributed dispersively and some dislocations existed in the dislocation tangle. On the other hand, with the increase in temperature and stress, as Fig. 5(d) shows, a great many dislocations existed in the form of dislocation tangles and the number of dispersively distributed dislocations decreased when the test condition was $1,050{ }^{\circ} \mathrm{C}$ and $20 \mathrm{MPa}$.

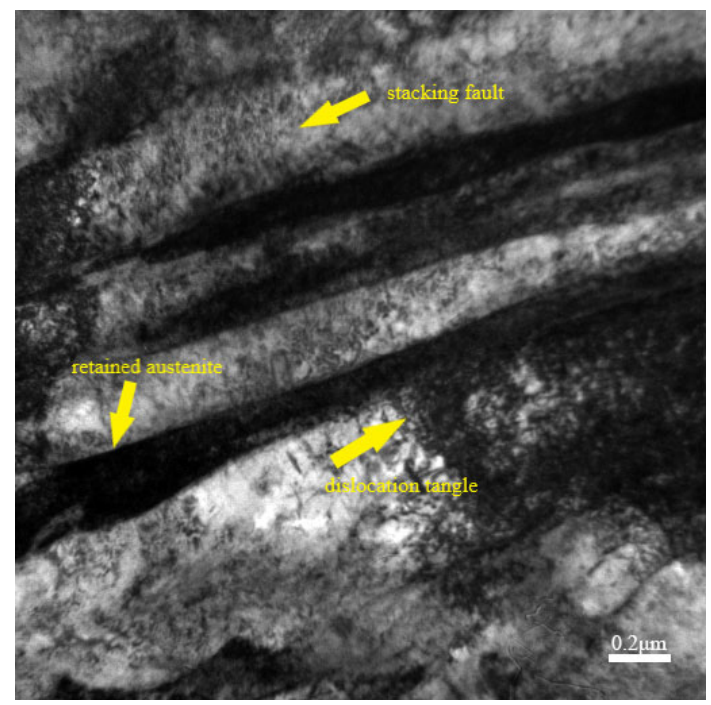

(a)

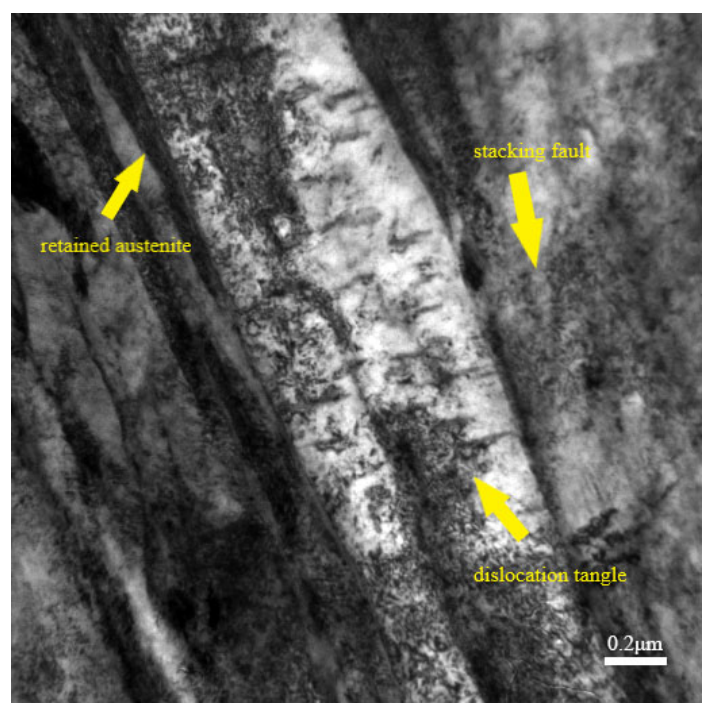

(c)

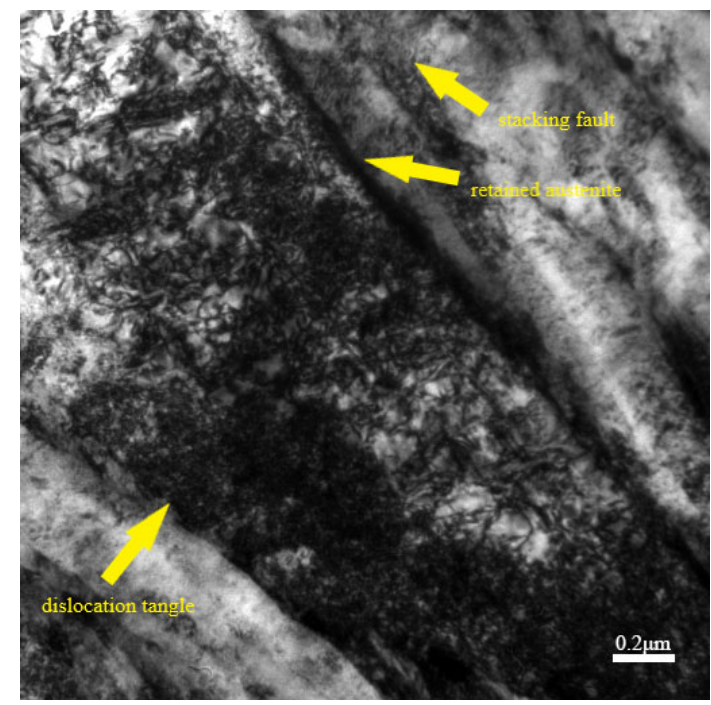

(b)

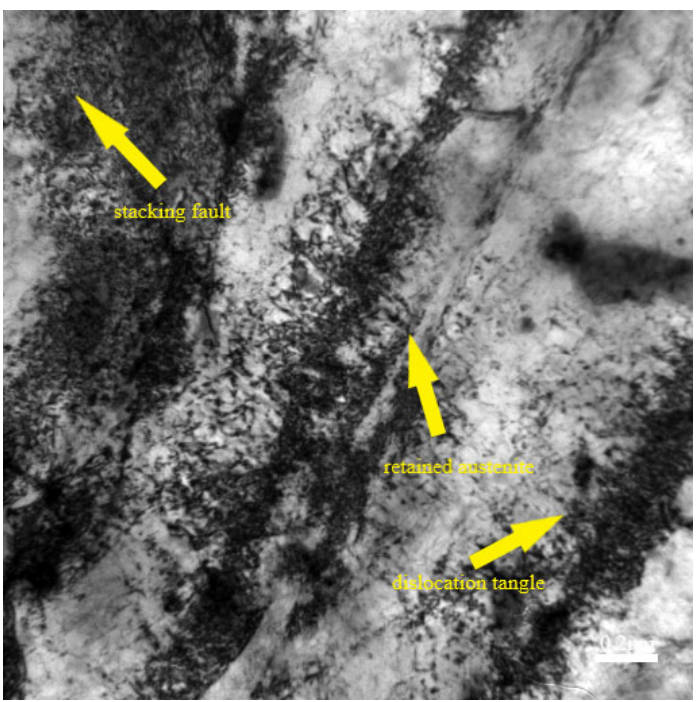

(d)

Fig. 6 TEM metallography under different conditions when magnification was 50,000 times: (a) $1,000{ }^{\circ} \mathrm{C}, 10 \mathrm{MPa}$; (b) $1,000{ }^{\circ} \mathrm{C}, 20 \mathrm{MPa}$; (c) $1,050{ }^{\circ} \mathrm{C}, 10 \mathrm{MPa}$; (d) $1,050{ }^{\circ} \mathrm{C}, 20 \mathrm{MPa}$.

When the magnification was 50,000 times, as Fig. 6 shows, there were some subtle stacking faults besides many obvious dislocations. Figs. 6(a)-6(d) also illustrate the microstructure of the Q460E steel specimens after having undergone high temperature tensile creep tests under different test conditions were predominately lath martensite arranged in bunches. The laths roughly paralleled to each other inside martensite, but their width and the length differed from one another. Besides the martensite arranged in bunches, retained austenite could also be seen in Fig. 6. The martensite laths which were arranged tightly had a straight interface and they were separated from each other by retained austenite. 
Y. Sui, X. Zhang

L. Guo, D. Xu

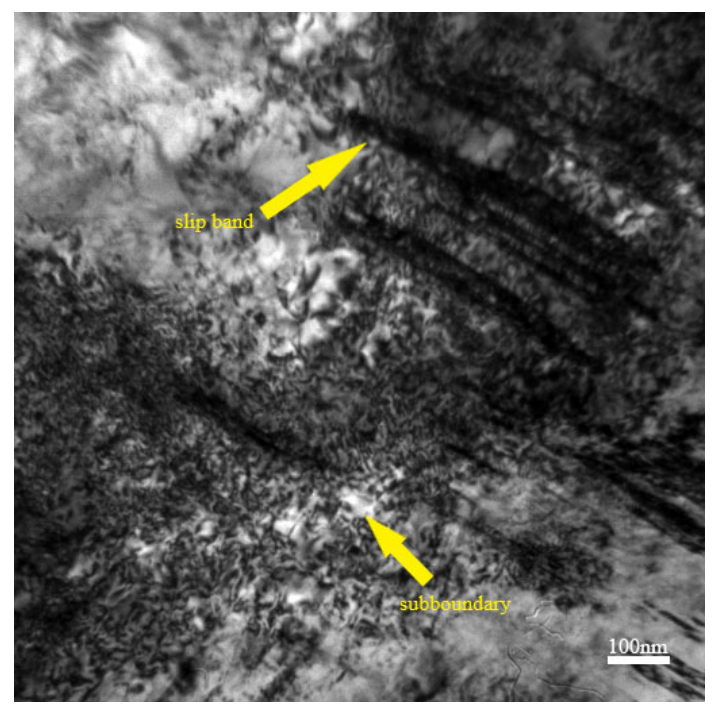

(a)

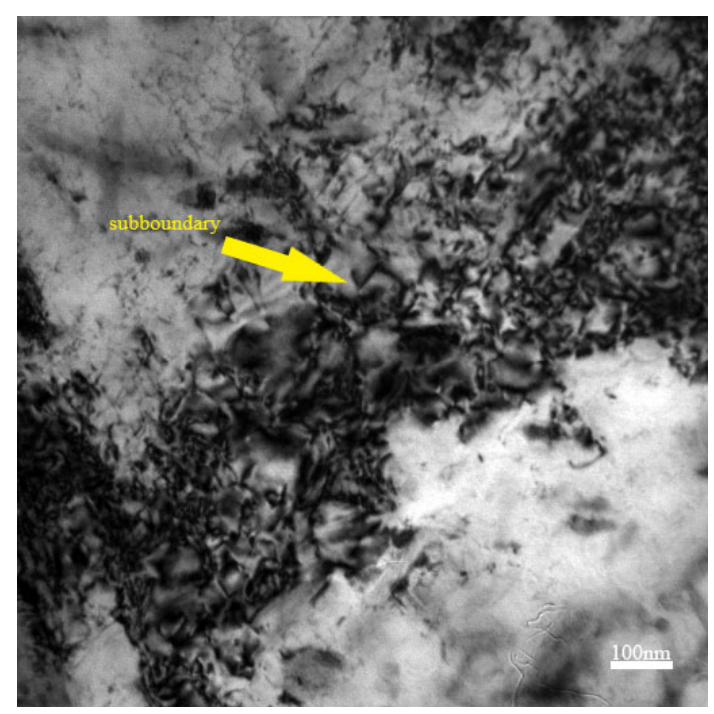

(c)
High Temperature Creep Microstructure Study of Q460E Steel Based on Solidification Method

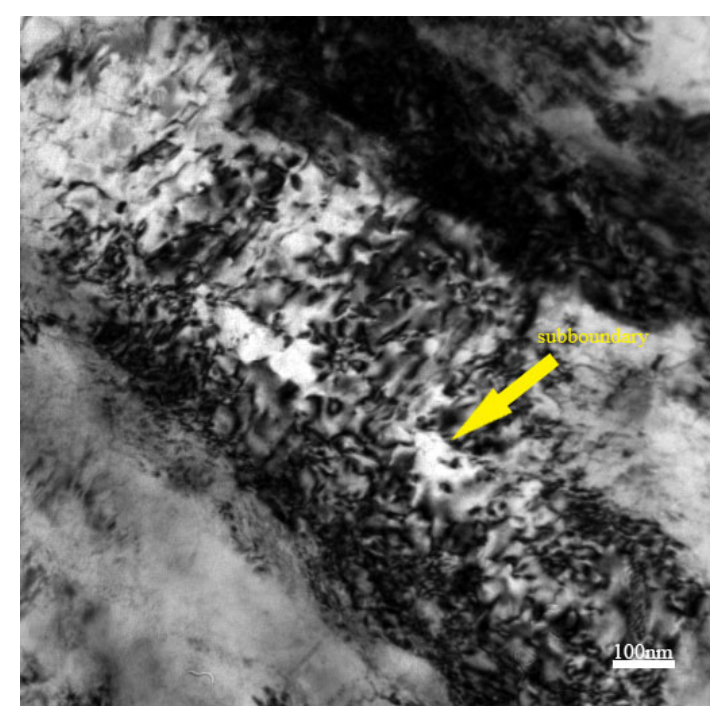

(b)

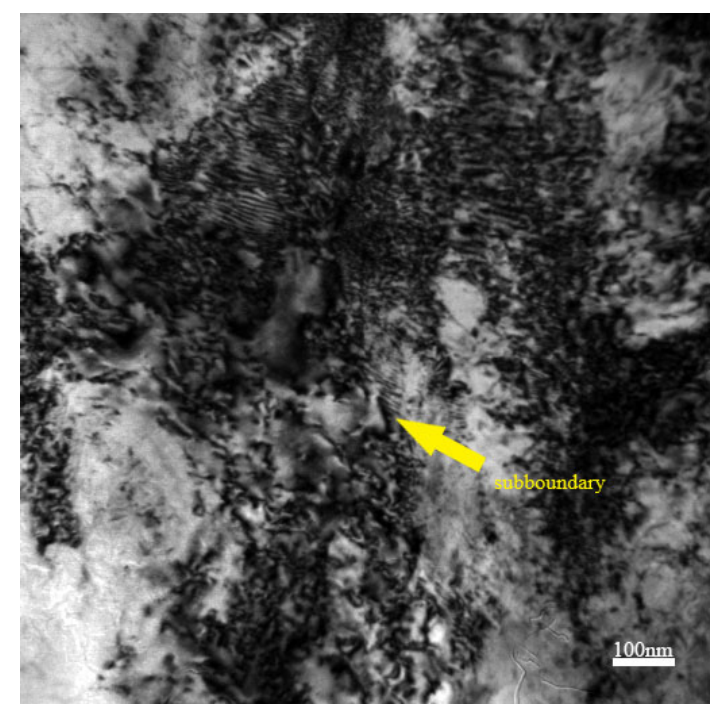

(d)

Fig. 7 TEM metallography under different conditions when magnification was $1 \times 10^{6}$ times:

(a) $1,000{ }^{\circ} \mathrm{C}, 10 \mathrm{MPa}$; (b) $1,000{ }^{\circ} \mathrm{C}, 20 \mathrm{MPa}$; (c) $1,050{ }^{\circ} \mathrm{C}, 10 \mathrm{MPa}$; (d) $1,050{ }^{\circ} \mathrm{C}, 20 \mathrm{MPa}$.

When the magnification was further increased to $1 \times 10^{6}$ times, as shown in Fig. 7, a subboundary gradually formed. In Fig. 7(a), there were some apparent slip bands and only a little formed subboundary. When the test stress and temperature were increased, as Figs. 7(b)7(d) show, more subboundaries formed and became more obvious. When Fig. 7(a) and Fig. 7(b) are compared, it could be found that at the same test temperature, the subboundary increased gradually with the increase in the stress value. The same phenomenon could be observed in Fig. 7(c) and Fig. 7(d).

Summing up, during the process of high temperature creep deformation of the Q460E steel, plenty of dislocations and dislocation substructures appeared inside the crystalline grain and at the boundary of the crystalline grain. Dislocations and their substructures migrated under the combined action of high temperature and creep stress, which is the root cause which triggered the creep deformation. High dislocation density could form dislocation walls and tangles. The increase in dislocation density made the intercrystalline energy become higher, which prompted the dislocation to be annihilated and rearranged where the dislocation walls 
and tangles existed, and the dislocation walls and tangles developed into a low angle subboundary. The form of the subboundary provided positive effect on the process of creep.

\section{Conclusions}

The creep curve drawn from the tensile creep test data at a high temperature showed that when the material was subjected to a relatively low tensile stress at a certain test temperature, the steady-state creep stage could last for a relatively long time. When the tensile stress value was higher, the time of the steady-state creep stage was shorter. When the tensile stress was constant, the trend of the curves showing the relationship between creep strain and time was basically the same at different test temperatures. The difference was that when the temperature increased, the value of the creep strain was much higher. It could be inferred from the above findings that when the tensile stress was constant, the effect of the test temperature on creep deformation was not as great as that of the tensile stress value on the creep strain when the test temperature was constant.

The microstructure of the Q460E steel after having undergone the high temperature tensile creep test and water quenching and observed with a metallographic microscope was mainly lath-like martensite and retained austenite. The laths of martensite were separated with small angle grain boundaries, while large angles existed between bunches of martensite. The carbide particles, which were separated from martensite and were distributed in grains and at boundaries, made the grain boundaries appear more clearly. And at the temperature of 1,050 ${ }^{\circ} \mathrm{C}$, there was also some bainite appearing at the grain boundary.

The microstructure of the Q460E steel after high temperature creep deformation observed with a TEM was principally lath-like martensite arranged in bunches. The martensite laths separated by retained austenite were roughly parallel to each other positionwise but differed in width and length from one another. There were plenty of noticeable dislocations and their substructures between the martensite laths. It was precisely because of the dislocation rising and the subboundary forming that a favourable condition for the creep deformation existed.

\section{REFERENCES}

[1] Mu, X.Y. Creep mechanics. Xi'an Jiaotong University Press: Xi'an, China, 1990; 1, 4-5.

[2] Wang, W.Y.; Yan, S.H.; Liu, J.P. Studies on temperature induced creep in high strength Q460 steel, Materials and Structures 2017, 50,68. https://doi.org/10.1617/s11527-016-0941-2

[3] Wang, W.Y.; Yan, S.H. Creep Behavior in High Strength Q460 Steel, Journal of Tongji University (Natural Science) 2016, 44 (6), 830-837.

[4] Jones, D.R.H.; Ashby, M.F. Engineering materials 1: An introduction to properties, applications and design. Elsevier: New York, USA, 2011; 312-313.

[5] Ottosen, N.S.; Ristinmaa, M. The mechanics of constitutive modeling. Elsevier: Amsterdam, Holland, 2005; 387-388.

[6] Brimacombe, J.K.; Sorimachi, K. Crack Formation in the Continuous Casting of Steel, Metallurgical Transactions B 1977, 8 (2), 489-505. https://doi.org/10.1007/bf02696937

[7] Fachinotti, V.D.; Cardona, A. Constitutive models of steel under continuous casting conditions, Journal of Materials Processing Technology 2003, 135 (1), 30-43. https://doi.org/10.1016/s0924-0136(02)00955-x

[8] Huang, J.H. Analysis of creep properties of metal materials at high temperature, China New Technologies and Products 2012, 9, 141.

[9] Guo, L.; Zhang, X.Z.; Feng, C.X. Effects of high-temperature creep property on straightening deformation of continuous casting slab, Iron and Steel 2017,52 (2), 38-43.

[10] Zhang, X.Z.; Guo, L.; Feng, C.X. New straightening Technology of Continuous Casting Slabs Based on High-temperature Creep Properties, China Mechanical Engineering 2017, 28 (10), 1232-1237. 
[11] Kang, X.D.; Di, H.S.; Zhang, X.M. High temperature mechanical property of low carbon steel, Journal of Materials and Metallurgy 2003, 2 (1), 59-62.

[12] Luo, S.J.; Huo, W.C.; Hu, L.X. High-temperature Mechanical Properties of Carbon Steel on Gleeble1500 Experimental Machine, Iron and Steel 1991, 26 (8), 54-57.

[13] Seol, D.J.; Won, Y.M.; Oh, K.H.; Shin, Y.C.; Yim, C.H. Mechanical Behavior of Carbon Steels in the Temperature Range of Mushy Zone, ISIJ International 2000, 40 (4), 356-363. https://doi.org/10.2355/isijinternational.40.356

[14] Guo, L.; Sui, Y.H.; Zhang, X.Z. High-temperature creep constitutional model of Q460E steel and effect of creep on bulging deformation of continuous casting slab, Journal of Iron and Steel Research 2018, 25, 1123-1130. https://doi.org/10.1007/s42243-018-0169-1

[15] Liang, N.W.; Liu, D.Y.; Liu, S.C. Effect of Heat Treatment on the Microstructure and Properties of Low Alloy Structure Steel Q460E, Journal of Dalian Jiaotong University 2008, 29 (1), 84-88.

Submitted: $\quad 22.3 .2019$

Accepted: $\quad 08.10 .2019$
Yunhuan Sui

suiyunhuan123@sina.com

National Engineering Research Centre for Equipment and Technology of Cold Strip

Rolling, Yanshan University,

Qinhuangdao 066004, Hebei, P. R. China

Xingzhong Zhang*

zhangxzh@ysu.edu.cn

National Engineering Research Centre for Equipment and Technology of Cold Strip

Rolling, Yanshan University,

Qinhuangdao 066004, Hebei, P. R. China

Long Guo

Ling Yun Industrial Co., Ltd.,

Baoding 071000, Hebei, P. R. China

Dianfeng Xu

AEEC Changchun Control Technology

Co., Ltd.,

Changchun 130102, Jilin, P. R. China

*Corresponding author,

zhangxzh@ysu.edu.cn 